\title{
Cusp Prolapse Timing
}

National Cancer Institute

\section{Source}

National Cancer Institute. Cusp Prolapse Timing. NCI Thesaurus. Code C127555.

The time point during the cardiac cycle when the prolapse of of one or more cusps occurs. 